\title{
Food and feed consumption of lemon butterfly, Papilio demoleus under laboratory conditions
}

\author{
Wali Muhammad Mangrio ${ }^{1}$, Hakim Ali Sahito ${ }^{1,2^{*}}$, Noor Hussain \\ Chandio ${ }^{3}$, Tasneem Kousar ${ }^{1}$, Zafar Hussain Shah ${ }^{1}$, Nisar Ahmed \\ Khaskheli ${ }^{4}$ and Faheem Ahmed Jatoi ${ }^{1}$
}

1. Department of Zoology, Faculty of Natural Sciences, Shah Abdul Latif University, Khairpur Mir's, SindhPakistan

2. Date Palm Research Institute (DPRI), SALU, Khairpur-Pakistan

3. Department of Geography, SALU, Khairpur-Pakistan

4. Department of Physical Education, SALU, Khairpur-Pakistan

*Corresponding author's email: hakim.sahito@salu.edu.pk

Citation

Wali Muhammad Mangrio, Hakim Ali Sahito, Noor Hussain Chandio, Tasneem Kousar, Zafar Hussain Shah, Nisar Ahmed Khaskheli and Faheem Ahmed Jatoi. Food and feed consumption of lemon butterfly, Papilio demoleus under laboratory conditions. Pure and Applied Biology. Vol. 9, Issue 1, pp340-351.

http://dx.doi.org/10.19045/bspab.2020.90039

Received: 10/08/2019 Revised: 25/10/2019

Accepted: 01/11/2019

Online First: 06/11/2019

\section{Abstract}

The research studies were carried out from egg to adult stages of pest on host citrus lemon leaves and the collection was made from the lemon orchards inter-cropped with date palm orchards. A couple of male and female adult butterflies were released for eggs lying which were laid singly on tender twigs or under the surface of the leaves, oviposition usually takes place early morning hours then eggs were got separated in Petri dishes based on eight treatments that were replicated 3 times. When those eggs hatched in the first stage of larvae, were awarded weight food in grams for checking its proper food consumption. All larval stages were given fresh leaves as a source of food, weight in grams with an overall mean of $1^{\text {st }}$ instar's (1.21 to 1.36$), 2^{\text {nd }}$ (1.36 to 1.45$), 3^{\text {rd }}$ (1.51 to 1.72$)$ and $4^{\text {th }}$ (1.76 to 1.89$)$, and $5^{\text {th }}$ (1.94 to 2.19$)$. After consumption of food, the remaining food was measured in grams with the overall mean of $1^{\text {st }}$ instar's $(0.80$ to 1.13$), 2^{\text {nd }}$ (0.60 to 0.77$), 3^{\text {rd }}(0.55$ to 0.59$), 4^{\text {th }}(0.55$ to 0.58$)$ and $5^{\text {th }}(0.51$ to 0.58$)$ in grams, respectively which were found significantly different to each other $\mathrm{p}=0.001$. It was concluded that the larval stages of pest found voracious feeder of the citrus plants, therefore, it is recommended that these larval stages are capable to manage through IPM, techniques by which we can save the lemon orchards.

Keywords: Larval stage; Nourishments; Oviposition; $P$. demoleus; Voracious feeder Introduction

Citrus fruits are cosmopolitan and an important leading crop of the world grown tropical and sub-tropical regions [1]. Mostly; cultivated Israel, Japan, Brazil, Algeria, China, Argentina, Italy, Central America, India, Pakistan, Egypt, Bangladesh, Mexico, Palestine, Japan, New Zealand, Russia, Paraguay, Uruguay, and Spain, etc., and citrus fruits are refreshing, delicious, sources 
of minerals, vitamins $\mathrm{C}$ and $\mathrm{P}$, which keep the blood pressure at normal rate and necessary substances for the human beings [2]. Lemon juice is used in medicinal values and for flavouring in certain dishes, cold drinks, meat, salads, fish and their pulses source of food for cattle animals [3].

The Papilio genus is dispersed in many parts of the world including, Australia, New Guinea, Pakistan, Japan, China, Indonesia, Iran, India, Formosa [4]. It was first documented the potential power of extensive migration and rapid growth rate $[5,6]$. Butterflies respond rapidly to environmental changes, high visual, olfactory responses and valuable plant pollination [7] and agriecosystem is their favorable habitat for their fruitful survival and found throughout the year. Butterflies, most extensive order among arthropods, a symbol of beauty [8] can be easily mounted, identified, various species can puzzle due to coloration, the female is larger compared the male but dense population density relies on negative effect [9]. The most of the insects act as the plant pests, suck the juices from the plants, affect trunks, stems, leaves become yellow, turns pale in color, affect leaves, fruits, and terminal eventually fall off trees and resultant as the death of trees and cause severe economic losses. In fact; there are abundant insect pests which are harming the citrus plants orchids and nurseries cause severe economic losses of which some serious insect pest of citrus plants such as; $P$. demoleus Linnaeus, Diaphorina citri Kuwayama, Dialeurodes citri Ashmnead, Aonidiella aurantii Maskell, Phylloncistis citrella Stainton and $P$. polytes Linnaeus [10]. When there is a high population, the host plants decrease fruit production and retard plant growth and the intense invasion causes defoliation of the trees [11]. $P$. demoleus perform a dual role, pest, and pollinator and development depend on the availability of the host plants [12].
The life cycle of $P$. demoleus and their different Meta morphological patterns for the development in the different habitat of this pest in the agriculture ecosystem is necessary because some time $P$. demoleus facing anxiety due to the unavailability of nectars and host plants. An adult using biting-chewing mouthparts, the main organs of the flower-visiting and their larvae stages have the association with vascular plants to drink floral sap and also other liquid substances from the host plants [13]. The food and feeding consumption behaviours of $P$. demoleus were observed in present research work because knowledge on this matter is an authentic source for their conservation, pest influence, and management. Keeping in view, the citrus orchards are cultivated throughout the province of Sindh but abundantly growing in District: Naushahro Feroze as on productive basis and this pest are vigorously damaging to the lemon plants and the nursery which are cultivated under date palm shadows. Therefore; this research study was carried out to know the food and feeding consumption of lemon butterflies for their proper control measure.

\section{Materials and methods}

Feeding efficacy of Lemon butterfly, $P$. demoleus larvae under laboratory conditions

The research on different larval stages of Papilio demoleus Linnaeus was carried out from March to May 2019, dreaming and prominent appearance of larvae on lemon orchids. The collection was brought at Date Palm Research Institute (DPRI), Entomology laboratory, Shah Abdul Latif University, Khairpur- Sindh- Pakistan. From different locations and most cultivated areas of District; Naushahro Feroze, Sindh, the collections were made. During collection different growing stages of pests such as; eggs, larvae, pupae and an adults were collected from the fresh lemon plantation 
and newly growing lemon nurseries form different fertile areas of the same district. An adult paired $P$. demoleus was given $10 \%$ sugar solution through cotton soaked rolls inside mosquito net as the source of food for feeding. The research study was carried out from the newly emerged eggs when produced a first larval stage of the pest and the research based on objectives were initiated. In this method, a mosquito net containing muslin cloth sleeve was attached at one side of the net for feeding, cleaning, and handling facilitate inside the cage.

Then fresh nursery plants possessing few twigs up to 2 feet of a lemon plant were kept in each mosquito cage for oviposition to start the research work whereas; freshly collected leaves from Fruit Garden of DPRI, SALU - Khairpur were replaced on an alternate day as a food and feed of larval stages. With the help of hygrometer, the percentage of relative humidity and room temperature were recorded at the source of 12L: 12D (L: Light and D: dark). The larvae were also reared in plastic jars of same stage/days and the food was provided fresh leaves of host plants until pupation. The research trials were conducted on 8 treatments and replicated 3 times under laboratory conditions. The Petri dishes were kept cleaned on a daily basis by removing the waste including larvae faecal material and given fresh food to larvae. As time passes larvae grew in size and now larvae required more space then larvae were shifted to large diameter Petri dishes containing $(15.5 \mathrm{~cm})$ diameter with the help of camel hairbrush and all stages larvae were examined thoroughly. From the first stage up to the fifth stage of larvae were provided food and feed consumption was determined by weighing through an electronic weight machine for the data collection. Slowly and gradually; the larvae converted into pupae in which, the wings, legs, antennae, abdomen prominently appeared to prolong the life cycle to be an adult either male or female.

\section{Statistical analysis}

The data were statistically analyzed, the analysis of variance (ANOVA) was done though the Randomized Complete Block Design (RCBD) for different food and feed consumption parameters and means were separated by using LSD through statistical software student package version, Statistics 8.1. USA.

\section{Results}

\section{Larval stages were given weight food in grams}

In the present research study, a paired defensive organ was found in the anterior segment act as defensive and other functions to produce a secretion from osmeterium. When the larvae changed one stage to next they shed out their cuticle layer and very immediately turned their body and more prefer for feeding. Food and feed consumption of lemon butterfly, all larval stages given fresh leaves as a source of food in grams with an overall mean to $1^{\text {st }}$ instar's (1.21 to 1.36$), 2^{\text {nd }}(1.36$ to 1.45$), 3^{\text {rd }}(1.51$ to $1.72)$ and $4^{\text {th }}(1.76$ to 1.89$)$, and $5^{\text {th }}$ (1.94 to 2.19), respectively. Thus; it was observed that the fifth stage larval duration went up to five days with an average of given food minimum to the first stage and maximum to the fifth stage, respectively. The analysis of variance shows the significant difference among food consumed at $1^{\text {st }}$ to $5^{\text {th }}$ stages larvae such as; $1^{\text {st }}$ stage larvae $(D F=7$; $\mathrm{F}=10.05 ; \quad \mathrm{P}=0.00), \quad 2^{\text {nd }}$ stage $\quad(\mathrm{DF}=7 ;$ $\mathrm{F}=43.79 ; \mathrm{P}=0.00), 3^{\text {rd }}$ stage $(\mathrm{DF}=7 ; \mathrm{F}=5.72$; $\mathrm{P}=0.00), 4^{\text {th }}$ stage $(\mathrm{DF}=7 ; \mathrm{F}=6.80 ; \mathrm{P}=0.00)$, and $5^{\text {th }}$ stage $(\mathrm{DF}=7 ; \mathrm{F}=6.80 ; \mathrm{P}=0.00)$ whereas; the least significant difference allpairwise comparisons also shows the significant difference among all treatments awarded food in grams as described in alphabetic letters, their specified justification has been provided in under given (Table 1). 


\section{Larval stages remaining weight food in grams}

Similarly; after the consumption of fresh food remaining food was observed in grams and weight minimum to maximum in grams with the help of an electronic digital weighing machine. The fifth instar larvae were in all aspects that were observed different from previous four instars, tapered anteriorly, cylindrical in shape, green in color. Behind the head, fleshy spines were located and with their differences in numbers such as; four, eighth and ninth sternum segment contained brownish strips and two yellowish semi-circular bands on the eminent region of the body, these spines gradually modified from yellow-orange to darker green in color. On second thoracic two eyes like the spots were observed with a pale green head and last body segment consisted horn-like structure. After consumption food the remaining food was measured in grams with the overall mean of $1^{\text {st }}$ instar $(0.80$ to 1.13$), 2^{\text {nd }}$ instar $(0.60$ to $0.77), 3^{\text {rd }}$ instar $(0.55$ to 0.59$), 4^{\text {th }}$ instar (0.55 to 0.58$)$ and $5^{\text {th }}$ instar $(0.51$ to 0.58$)$ in grams, respectively (Table 2 ). The analysis of variance shows the significant difference among the $1^{\text {st }}$ to $5^{\text {th }}$ stages larvae remaining food in grams in all treatments such as; in $1^{\text {st }}$ stage larvae $(\mathrm{DF}=7 ; \mathrm{F}=1.33 ; \mathrm{P}=0.28), 2^{\text {nd }}$ stage $(\mathrm{DF}=7 ; \mathrm{F}=5.50 ; \mathrm{P}=0.00), 3^{\text {rd }}$ stage $(\mathrm{DF}=7 ; \mathrm{F}=0.68 ; \mathrm{P}=0.68), 4^{\text {th }}$ stage $(\mathrm{DF}=7$; $\mathrm{F}=31.69 ; \mathrm{P}=0.00)$, and $5^{\text {th }}$ stage $(\mathrm{DF}=7$; $\mathrm{F}=14.18 ; \mathrm{P}=0.00$ ) and all-pairwise (LSD) comparisons also shows the significant difference which are divided into homogeneous groups as described as under given table.

\section{Larval stages make loops at a distance of 5 centimetres}

On citrus plant leaves; the total duration of third-stage larvae was observed up to 5 days that usually make loops with the minimum and maximum level to reach 5-centimeter distance. On the basis of body coloration and morphological appearance was similar but contained bit differentiation in body size, third instar larvae resemble as second and first instar as well. The first instar larvae makes loops to reach at the distance of five centimetres with the overall mean from first to fifth larvae such as; $1^{\text {st }}$ instar larvae (74.88 to 92.38$), 2^{\text {nd }}$ instar (62.38 to 70.25$)$, $3^{\text {rd }}$ instar (47.75 to 60.25$), 4^{\text {th }}$ instar $(41.38$ to 45.25$)$ and $5^{\text {th }}$ instar (17.88 to 39.38$)$, respectively. The analysis of variance shows the significant difference among $1^{\text {st }}$ to $5^{\text {th }}$ stages larvae in making loops within all treatments such as; $1^{\text {st }}$ stage $(\mathrm{DF}=7 ; \mathrm{F}=6.57$; $\mathrm{P}=0.00), 2^{\text {nd }}$ stage $(\mathrm{DF}=7 ; \mathrm{F}=0.77 ; \mathrm{P}=0.61)$, $3^{\text {rd }}$ stage $(\mathrm{DF}=7 ; \mathrm{F}=1.67 ; \mathrm{P}=0.15), 4^{\text {th }}$ stage $(\mathrm{DF}=7 ; \mathrm{F}=2.36 ; \mathrm{P}=0.06)$, and $5^{\text {th }}$ stage $(\mathrm{DF}=$ $7 ; \mathrm{F}=3.40 ; \mathrm{P}=0.00)$, respectively. A further and all-pairwise (LSD) comparison also shows the significant differences which are divided into homogeneous groups as described in under given (Table 3). Further the fresh food of lemon leaves were awarded to the all larval stages such as, $1^{\text {st }}, 2^{\text {nd }}, 3^{\text {rd }}$, $4^{\text {th }}$ and $5^{\text {th }}$ larvae at early in the morning at (9:AM). Before food was given it was measured through weight gram digital electronic machine and after 24 hours the remaining food was measured in grams for the purpose of data collection and finally the faecal released material were also measured in grams and described in under given photo gallery (Fig. 1). 
Table 1. Given food in grams to Lemon butterfly at larval stages under laboratory conditions

\begin{tabular}{|c|c|c|c|c|c|c|c|c|c|}
\hline \multicolumn{10}{|c|}{ Development of first stage / larvae consumed different days } \\
\hline Days & $\mathbf{T}_{1}$ & $\mathbf{T}_{2}$ & $\mathbf{T}_{\mathbf{3}}$ & $\mathbf{T}_{4}$ & $\mathbf{T}_{5}$ & $\mathbf{T}_{6}$ & $\mathbf{T}_{7}$ & $\mathbf{T}_{8}$ & Mean \pm SD \\
\hline $1^{\text {st }}$ & 1.20 & 1.21 & 1.22 & 1.17 & 1.18 & 1.19 & 1.23 & 1.24 & $1.21 \pm 0.01^{\mathrm{b}}$ \\
\hline $2^{\text {nd }}$ & 1.17 & 1.18 & 1.21 & 1.22 & 1.23 & 1.25 & 1.28 & 1.29 & $1.23 \pm 0.02^{\mathrm{b}}$ \\
\hline $3^{\text {rd }}$ & 1.26 & 1.28 & 1.31 & 1.32 & 1.35 & 1.39 & 1.4 & 1.43 & $1.34 \pm 003^{\mathrm{a}}$ \\
\hline $4^{\text {th }}$ & 1.3 & 1.31 & 1.32 & 1.35 & 1.38 & 1.39 & 1.41 & 1.42 & $1.36 \pm 0.04^{\mathrm{a}}$ \\
\hline \multicolumn{10}{|c|}{ Second stage } \\
\hline $1^{\text {st }}$ & 1.29 & 1.33 & 1.34 & 1.36 & 1.33 & 1.36 & 1.4 & 1.44 & $1.36 \pm 0.05^{b}$ \\
\hline $2^{\text {nd }}$ & 1.21 & 1.24 & 1.27 & 1.31 & 1.32 & 1.31 & 1.32 & 1.37 & $1.29 \pm 0.04^{\mathrm{c}}$ \\
\hline $3^{\text {rd }}$ & 1.23 & 1.24 & 1.25 & 1.27 & 1.29 & 1.3 & 1.34 & 1.36 & $1.29 \pm 0.03^{\mathrm{c}}$ \\
\hline $4^{\text {th }}$ & 1.39 & 1.4 & 1.41 & 1.44 & 1.45 & 1.48 & 1.49 & 1.55 & $1.45 \pm 0.02^{\mathrm{a}}$ \\
\hline \multicolumn{10}{|c|}{ Third stage } \\
\hline $1^{\text {st }}$ & 1.41 & 1.46 & 1.47 & 1.51 & 1.52 & 1.53 & 1.6 & 1.61 & $1.51 \pm 0.01^{\mathrm{d}}$ \\
\hline $2^{\text {nd }}$ & 1.6 & 1.61 & 1.54 & 1.55 & 1.56 & 1.59 & 1.63 & 1.55 & $1.58 \pm 0.02^{\mathrm{c}}$ \\
\hline $3^{\text {rd }}$ & 1.6 & 1.61 & 1.64 & 1.65 & 1.68 & 1.71 & 1.73 & 1.71 & $1.67 \pm 0.03^{b}$ \\
\hline $4^{\text {th }}$ & 1.69 & 1.7 & 1.71 & 1.7 & 1.72 & 1.74 & 1.73 & 1.74 & $1.72 \pm 0.05^{\mathrm{a}}$ \\
\hline $5^{\text {th }}$ & 1.66 & 1.67 & 1.68 & 1.71 & 1.7 & 1.73 & 1.75 & 1.73 & $1.70 \pm 0.04^{\mathrm{a}}$ \\
\hline \multicolumn{10}{|c|}{ Fourth stage } \\
\hline $1^{\text {st }}$ & 1.68 & 1.71 & 1.76 & 1.79 & 1.78 & 1.8 & 1.79 & 1.76 & $1.76 \pm 0.05^{\mathrm{c}}$ \\
\hline $2^{\text {nd }}$ & 1.74 & 1.75 & 1.76 & 1.78 & 1.8 & 1.81 & 1.82 & 1.81 & $1.78 \pm 0.04^{\mathrm{b}}$ \\
\hline $3^{\text {rd }}$ & 1.83 & 1.85 & 1.88 & 1.87 & 1.89 & 1.92 & 1.9 & 1.92 & $1.88 \pm 0.03^{\mathrm{a}}$ \\
\hline $4^{\text {th }}$ & 1.89 & 1.87 & 1.88 & 1.91 & 1.92 & 1.88 & 1.89 & 1.9 & $1.89 \pm 0.02^{\mathrm{a}}$ \\
\hline \multicolumn{10}{|c|}{ Fifth stage } \\
\hline $1^{\text {st }}$ & 1.89 & 1.9 & 1.91 & 1.94 & 1.93 & 1.96 & 1.97 & 1.98 & $1.94 \pm 0.01^{\mathrm{d}}$ \\
\hline $2^{\text {nd }}$ & 2.08 & 2.09 & 2.1 & 2.12 & 2.13 & 2.11 & 2.1 & 2.09 & $2.10 \pm 0.02^{\mathrm{c}}$ \\
\hline $3^{\text {rd }}$ & 2.11 & 2.1 & 2.11 & 2.15 & 2.14 & 2.16 & 2.11 & 2.12 & $2.13 \pm 0.03^{\mathrm{bc}}$ \\
\hline $4^{\text {th }}$ & 2.08 & 2.12 & 2.13 & 2.14 & 2.15 & 2.19 & 2.2 & 2.21 & $2.15 \pm 0.04^{b}$ \\
\hline $5^{\text {th }}$ & 2.06 & 2.16 & 2.18 & 2.19 & 2.2 & 2.22 & 2.24 & 2.27 & $2.19 \pm 0.04^{\mathrm{a}}$ \\
\hline
\end{tabular}


Table 2. Remaining food in grams of Lemon butterfly larval stages

First larval stages remaining food weight in grams

\begin{tabular}{|c|c|c|c|c|c|c|c|c|c|}
\hline Days & $\mathbf{T}_{1}$ & $\mathbf{T}_{2}$ & $\mathbf{T}_{3}$ & $\mathbf{T}_{4}$ & $\mathbf{T}_{5}$ & $T_{6}$ & $\mathbf{T}_{7}$ & $\mathbf{T}_{8}$ & Mean \pm SD \\
\hline $1^{\text {st }}$ & 1.10 & 1.11 & 1.12 & 1.13 & 1.14 & 1.15 & 1.14 & 1.15 & $1.13 \pm 0.05^{\mathrm{a}}$ \\
\hline $2^{\text {nd }}$ & 0.85 & 0.88 & 0.86 & 0.83 & 0.86 & 0.81 & 0.82 & 0.83 & $0.84 \pm 0.04^{b}$ \\
\hline $3^{\text {rd }}$ & 0.77 & 0.78 & 0.8 & 0.82 & 0.83 & 0.86 & 0.85 & 0.86 & $0.82 \pm 0.03^{\mathrm{bc}}$ \\
\hline $4^{\text {th }}$ & 0.77 & 0.78 & 0.8 & 0.78 & 0.8 & 0.81 & 0.83 & 0.81 & $0.80 \pm 0.01^{\mathrm{c}}$ \\
\hline \multicolumn{10}{|c|}{ Second stage } \\
\hline $1^{\text {st }}$ & 0.73 & 0.75 & 0.76 & 0.78 & 0.76 & 0.79 & 0.8 & 0.81 & $0.77 \pm 0.05^{\mathrm{a}}$ \\
\hline $2^{\text {nd }}$ & 0.7 & 0.66 & 0.67 & 0.68 & 0.67 & 0.7 & 0.7 & 0.7 & $0.69 \pm 0.02^{b}$ \\
\hline $3^{\text {rd }}$ & 0.68 & 0.69 & 0.71 & 0.72 & 0.74 & 0.76 & 0.77 & 0.76 & $0.73 \pm 0.04^{\mathrm{c}}$ \\
\hline $4^{\text {th }}$ & 0.59 & 0.6 & 0.59 & 0.57 & 0.59 & 0.6 & 0.62 & 0.61 & $0.60 \pm 0.01^{\mathrm{d}}$ \\
\hline \multicolumn{10}{|c|}{ Third stage } \\
\hline $1^{\text {st }}$ & 0.56 & 0.57 & 0.59 & 0.6 & 0.59 & 0.55 & 0.56 & 0.55 & $0.57 \pm 0.04^{b}$ \\
\hline $2^{\text {nd }}$ & 0.66 & 0.67 & 0.62 & 0.63 & 0.64 & 0.55 & 0.57 & 0.58 & $0.62 \pm 005^{\mathrm{a}}$ \\
\hline $3^{\text {rd }}$ & 0.58 & 0.59 & 0.6 & 0.62 & 0.61 & 0.6 & 0.59 & 0.6 & $0.60 \pm 0.02^{\mathrm{a}}$ \\
\hline $4^{\text {th }}$ & 0.57 & 0.58 & 0.6 & 0.61 & 0.6 & 0.63 & 0.62 & 0.65 & $0.61 \pm 0.03^{\mathrm{a}}$ \\
\hline $5^{\text {th }}$ & 0.57 & 0.61 & 0.58 & 0.6 & 0.58 & 0.59 & 0.6 & 0.58 & $0.59 \pm 0.01^{\mathrm{ab}}$ \\
\hline \multicolumn{10}{|c|}{ Fourth stage } \\
\hline $1^{\text {st }}$ & 0.53 & 0.54 & 0.56 & 0.57 & 0.58 & 0.59 & 0.6 & 0.61 & $0.57 \pm 0.02^{\mathrm{ab}}$ \\
\hline $2^{\text {nd }}$ & 0.54 & 0.55 & 0.56 & 0.58 & 0.59 & 0.6 & 0.61 & 0.63 & $0.57 \pm 0.03^{\mathrm{a}}$ \\
\hline $3^{\text {rd }}$ & 0.52 & 0.53 & 0.54 & 0.56 & 0.54 & 0.55 & 0.57 & 0.56 & $0.58 \pm 0.05^{\mathrm{c}}$ \\
\hline $4^{\text {th }}$ & 0.5 & 0.51 & 0.52 & 0.53 & 0.54 & 0.55 & 0.57 & 0.58 & $0.55 \pm 0.01^{\mathrm{c}}$ \\
\hline \multicolumn{10}{|c|}{ Fifth stage } \\
\hline $1^{\text {st }}$ & 0.47 & 0.48 & 0.49 & 0.5 & 0.51 & 0.52 & 0.53 & 0.55 & $0.54 \pm 0.03^{\mathrm{c}}$ \\
\hline $2^{\text {nd }}$ & 0.53 & 0.54 & 0.55 & 0.57 & 0.58 & 0.59 & 0.61 & 0.63 & $0.51 \pm 0.01^{\mathrm{a}}$ \\
\hline $3^{\text {rd }}$ & 0.48 & 0.49 & 0.5 & 0.51 & 0.52 & 0.53 & 0.54 & 0.55 & $0.58 \pm 0.05^{\mathrm{c}}$ \\
\hline $4^{\text {th }}$ & 0.53 & 0.56 & 0.55 & 0.56 & 0.57 & 0.58 & 0.6 & 0.62 & $0.52 \pm 0.02^{\mathrm{ab}}$ \\
\hline $5^{\text {th }}$ & 0.55 & 0.57 & 0.55 & 0.54 & 0.56 & 0.58 & 0.57 & 0.55 & $0.57 \pm 0.04^{b}$ \\
\hline
\end{tabular}


Table 3. Lemon butterfly at larval stages make loops at a distance of 5 centimetres

\begin{tabular}{|c|c|c|c|c|c|c|c|c|c|}
\hline \multicolumn{10}{|c|}{ First larval stages loops } \\
\hline Days & $\mathbf{T}_{1}$ & $\mathbf{T}_{2}$ & $\mathbf{T}_{3}$ & $\mathbf{T}_{4}$ & $\mathbf{T}_{5}$ & $\mathbf{T}_{6}$ & $\mathbf{T}_{7}$ & $\mathbf{T}_{8}$ & Mean \pm SD \\
\hline $1^{\text {st }}$ & 90.00 & 98.00 & 92.00 & 94.00 & 92.00 & 91.00 & 92.00 & 90.00 & $92.38 \pm 0.92^{\mathrm{a}}$ \\
\hline $2^{\text {nd }}$ & 94.00 & 92.00 & 90.00 & 88.00 & 89.00 & 84.00 & 82.00 & 80.00 & $87.38 \pm 1.74^{\mathrm{b}}$ \\
\hline $3^{\text {rd }}$ & 84.00 & 86.00 & 90.00 & 82.00 & 80.00 & 78.00 & 79.00 & 78.00 & $82.13 \pm 1.52^{\mathrm{c}}$ \\
\hline $4^{\text {th }}$ & 80.00 & 78.00 & 76.00 & 74.00 & 76.00 & 72.00 & 73.00 & 70.00 & $74.88 \pm 1.16^{\mathrm{d}}$ \\
\hline \multicolumn{10}{|c|}{ Second stage } \\
\hline $1^{\text {st }}$ & 74.00 & 76.00 & 72.00 & 73.00 & 69.00 & 68.00 & 65.00 & 65.00 & $70.25 \pm 1.46^{\mathrm{a}}$ \\
\hline $2^{\text {nd }}$ & 65.00 & 72.00 & 69.00 & 65.00 & 64.00 & 68.00 & 73.00 & 71.00 & $68.38 \pm 1.22^{\mathrm{ab}}$ \\
\hline $3^{\text {rd }}$ & 65.00 & 68.00 & 62.00 & 64.00 & 66.00 & 71.00 & 66.00 & 69.00 & $66.38 \pm 1.02^{c}$ \\
\hline $4^{\text {th }}$ & 64.00 & 62.00 & 61.00 & 62.00 & 60.00 & 65.00 & 63.00 & 62.00 & $62.38 \pm 0.56^{\mathrm{d}}$ \\
\hline \multicolumn{10}{|c|}{ Third stage } \\
\hline $1^{\text {st }}$ & 62.00 & 61.00 & 66.00 & 63.00 & 58.00 & 55.00 & 61.00 & 56.00 & $60.25 \pm 1.31^{\mathrm{a}}$ \\
\hline $2^{\text {nd }}$ & 63.00 & 57.00 & 56.00 & 60.00 & 60.00 & 62.00 & 61.00 & 60.00 & $59.88 \pm 0.83^{\mathrm{a}}$ \\
\hline $3^{\text {rd }}$ & 57.00 & 54.00 & 56.00 & 53.00 & 52.00 & 51.00 & 52.00 & 56.00 & $53.88 \pm 0.79^{b}$ \\
\hline $4^{\text {th }}$ & 54.00 & 51.00 & 53.00 & 51.00 & 51.00 & 52.00 & 54.00 & 52.00 & $52.25 \pm 0.45^{b}$ \\
\hline $5^{\text {th }}$ & 52.00 & 50.00 & 48.00 & 46.00 & 48.00 & 47.00 & 46.00 & 45.00 & $47.75 \pm 0.82^{c}$ \\
\hline \multicolumn{10}{|c|}{ Fourth stage } \\
\hline $1^{\text {st }}$ & 46.00 & 47.00 & 46.00 & 45.00 & 44.00 & 45.00 & 44.00 & 45.00 & $45.25 \pm 0.37^{\mathrm{a}}$ \\
\hline $2^{\text {nd }}$ & 44.00 & 46.00 & 44.00 & 45.00 & 43.00 & 44.00 & 45.00 & 43.00 & $44.25 \pm 0.37^{\mathrm{ab}}$ \\
\hline $3^{\text {rd }}$ & 44.00 & 46.00 & 42.00 & 42.00 & 44.00 & 43.00 & 44.00 & 42.00 & $43.38 \pm 0.50^{b}$ \\
\hline $4^{\text {th }}$ & 40.00 & 42.00 & 41.00 & 44.00 & 38.00 & 42.00 & 44.00 & 40.00 & $41.38 \pm 0.73^{c}$ \\
\hline \multicolumn{10}{|c|}{ Fifth stage } \\
\hline $1^{\text {st }}$ & 39.00 & 42.00 & 38.00 & 36.00 & 40.00 & 41.00 & 43.00 & 36.00 & $39.38 \pm 0.92^{\mathrm{a}}$ \\
\hline $2^{\text {nd }}$ & 42.00 & 35.00 & 38.00 & 36.00 & 36.00 & 35.00 & 38.00 & 35.00 & $36.88 \pm 0.85^{b}$ \\
\hline $3^{\text {rd }}$ & 37.00 & 35.00 & 34.00 & 32.00 & 33.00 & 31.00 & 34.00 & 32.00 & $33.50 \pm 0.68^{c}$ \\
\hline $4^{\text {th }}$ & 33.00 & 28.00 & 25.00 & 24.00 & 22.00 & 25.00 & 23.00 & 28.00 & $26.00 \pm 1.25^{\mathrm{d}}$ \\
\hline $5^{\text {th }}$ & 22.00 & 21.00 & 18.00 & 19.00 & 16.00 & 18.00 & 14.00 & 15.00 & $17.88 \pm 0.99^{\mathrm{e}}$ \\
\hline
\end{tabular}




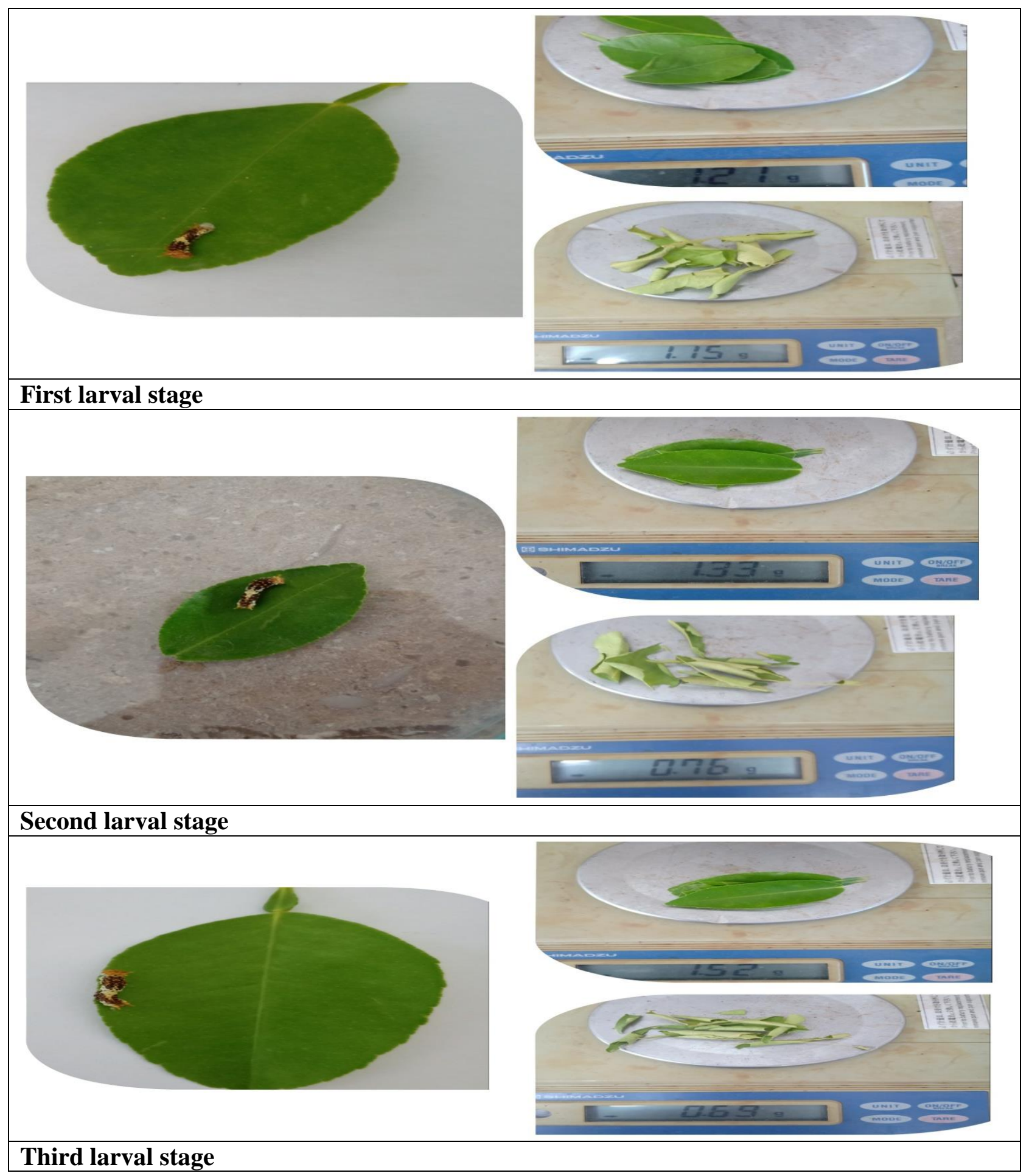




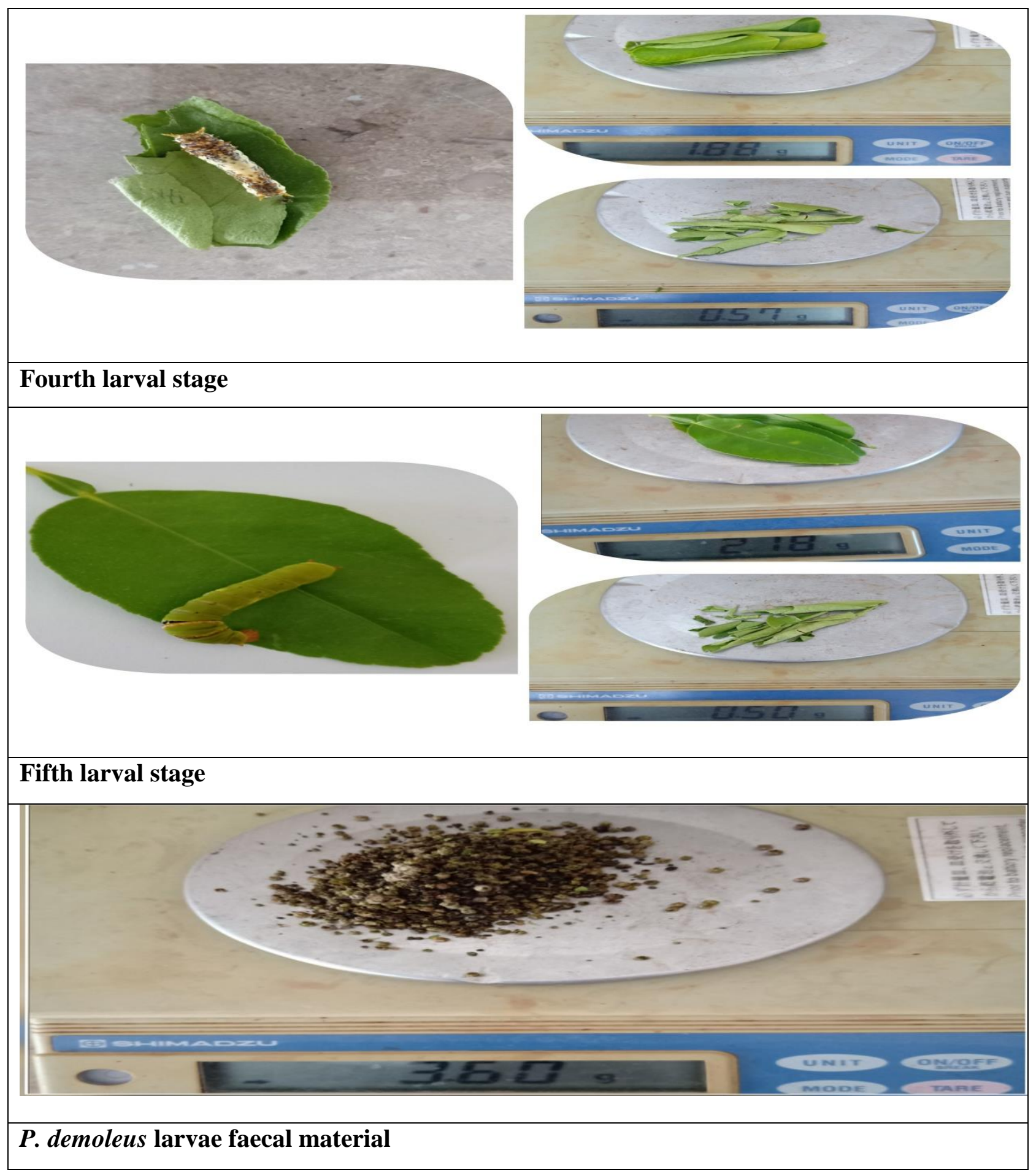

Figure 1. Photo gallery with different larval stages of lemon butterfly showing fresh and remanning food in grams

\section{Discussion}

During the research study, it was observed that the larvae of the lemon butterfly pass five stages and vigorously they are harming the citrus plantation. Lemon butterfly being a harmful insect pest not only survives in Sindh, Pakistan but also throughout the Indian sub-continent and several other 
countries of the world. This pest [14] has the potential power of extensive migration and rapid growth rate. $P$. demoleus being a plantpollinator had a rapid visual power, olfactory response and having intense power to respond rapidly fluctuation of environmental variations [15]. It was observed after fertilization females laid eggs under and the upper surface of tender twigs and shoots as well single manner which was creamy, pale yellow, smooth and flattened, compared with the work of [16]. When eggs becomes hatch larvae emerges, frequently by the source of camel hair brush first stage larvae were placed in separate petri dish and given fresh lemon leaves for further development after passing four days larvae comes in to second stage larvae but since from first days weight was taken in grams of fresh leaves by the source of weight machine and next day remaining food also repeatedly manner till first to fifth stage larvae. It was found that molting occurs in first-stage larvae and that cuticular layer was fed by larvae. First stage larvae took four days to conversion into the second stage. This finding is agreed with the compression work done by [17].

Each stage larvae changes into the next stage by casting/shed their cuticle and when cuticle was shaded from their body larvae immediately turned back and feed the cuticular layer for their nourishment. As larvae increase their length and structure now they are not only dependent on the cuticular layer but they having need of more amount of food then they start to search fresh especially newly growing lemon leaves and more harm to citrus plantation and cause massive economic loss to lemon orchards because lemon orchards are most valuable crop of this region. Further, it was described that, at this stage, larvae make slowly loops to find better shelter inside the fresh lemon leaves. The first stage larvae, darker brown, broad transverse off-white bands and shiny in color giving the larva 'a bird dropping' compared with the work of [18]. Second stage larvae morphologically similar to consume four days and may fed on edge portion up to midrib of the fresh leaves, the same findings were documented [19]. Third stage larvae consume five days in these stage larvae feed up to half portion and the terminal part of the growing shoots same findings documented. Fourth stage larvae passed four days consume more food as compared to the third stage by the compression research work of [7]. Fifth stages larvae take five days consumed maximum fresh food as compared to all other larval stages and make frequently loops inside the Petri dishes to search their nourishment and better shelter [19] reared at laboratory conditions four species of namely; $P$. polytes, $P$. polymnestor, $P$. helenus, and $P$. demoleus and documented nearly same result. This is with the agreement of [7]. During the observation, five distinct larval stages were observed [4]. In Pakistan also documented the same findings. It was calculated larvae starts to feed from first to the fifth stage but feed maximum at fifth stage and larvae shed their cuticle layer four times and after molting each time layers were eaten by larvae and same finding documented by [2]. Our results show that the total larval span consumed 22 days and the same observation was documented by [20]. Butterflies, most extensive order among arthropods can be easily mounted, identified, various species can puzzle due to coloration but dense population density relies negative upon [21]. Keeping in mind above precious ideas and present scientific work will be supportive to the people of Nuashahro Feroze, SindhPakistan. Most of the people/ farmers of this area are engaged by lemon plantation as their earning source. But unfortunately there is a lack of awareness in local people and severe economic loss occurs due to $P$. 
demoleus larval infestation. In this regard, the laboratory-based scientific study and IMP techniques should be a supportable and authentic tool for the lemon plant protection including lemon butterfly.

\section{Conclusion and recommendations}

It was concluded that during prominent breeding period male took initiative for copulation under and on the tender twig at morning time, was also observed in citrus orchards during the pest collection for this research. Female of $P$. demoleus fly's at a distance over the surface of the nursery and lemon plantation when a male wanted to mate, first vibrated their wings and holds female body tightly by the help of jointed appendages. This mating behaviour was observed inside the mosquito net at the time of food and feed consumption under DPRI, Entomology laboratory. In this regard, it is strictly important to carry out the immediate study on this pest to combat and provide essential information to the formers of this area and introduce IPM strategies for proper management. It is recommended that in district Naushahro Feroze lemon orchards is considered as bumper crop of this region but this golden crop is massively harmed by a potential insect pest $P$. demoleus and farmers face severely yield and economic losses. It felt dire need to bring awareness to the local people of this area and proper management for this insect pest which was kept as a key tool for this research. But for proper management of any insect pest, it is essential to study the biology and feeding consumption of the insect. In fact, there is no such type of scientific work and proper knowledge and management, feeding behaviours, host plant leaf consumption in this region has been reported previously. In this regard for fruitful production and beneficial profitability, this scientific documentary will be a helpful tool.

\section{Authors' contributions}

Conceived and designed the experiments: HA Sahito \& NH Chandio, Performed the experiments: WM Mangrio \& T Kousar, Analyzed the data: ZH Shah, Contributed materials/ analysis/ tools: NA Khaskheli \& FA Jatoi, Wrote the paper: HA Sahito \& WM Mangrio.

\section{Acknowledgment}

The authors are highly thankful to farmers of the district, Naushahro Feroze for providing the supportive hands during the collection from their nurseries and form houses. Again warmly thanks to Dean, Faculty of Natural Science and Director (DPRI) of their restless efforts and availed all need-based services at (DPRI) Entomology Laboratory, where present research was conducted.

\section{References}

1. Hayes WB (1957). Fruit growing in India. Kitabistan, Allahabad, India, Pp.154.

2. Homziak $\mathrm{T}$ Nicholas $\mathrm{T} \&$ Homziak $\mathrm{J}$ (2006). Papilio demoleus (Lepidoptera: Papilionidae): A new record for the United States, Commonwealth of Puerto Rico. Florida Entomol 89: 485-488.

3. Crane J (1955). Imaginal behaviour of a Trinidad butterfly, Heliconius erato hydara Hewitson, with special reference to the social use of color. Zoologica 40: 167-196.

4. Ganguli RN \& Ghosh MR (1967). Biology of Papilio demoleus pest of citrus in Tripura state. Indian Agricul 11:13-18.

5. Ahsan M \& Javaid I (1975). A contribution to the butterflies of Lahore with the addition of new records. Biologia 24: 238-247.

6. Badawi A (1981). Studies on some aspects of the biology and ecology of the citrus butterfly Papilio demoleus L. in Saudia Arabia (Papilionidae, Lepidoptera). J Z Angew Entomlo 91: 286-292. 
7. Asokan R (1997). Mass rearing and an additional instar of Papilio demoleus $\mathrm{L}$. on the acid lime, Citrus aurantifolia Swingle. Insect Envt 2: 128-129.

8. Radke SG \& Kandalkar HG (1988). Biology of lemon butterfly, Papilio demoleus Linnaeus (Lepidoptera: Papilionidae) in Vidarbha. Bull Entomol 29: 164-167.

9. Moonen JJM (1999). Papilio demoleus L. (Lepidoptera: Papilionidae) in West Irian. Trans. Lepidop. Soc Japan 50: 82-84.

10. Guerrero KA Eloz DV Boyce SL \& Farrell BD (2004). First New World documentation of an Old World citrus pest, the Lime Swallowtail Papilio demoleus (Lepidoptera: Papilionidae), in the Dominican Republic (Hispaniola). American Entomol 50: 227-229.

11. Dunn KL (1999). Butterfly observations in Southeast Asia including two potentially new records for Borneo. Victo Entomol 29: 114-116.

12. Pathak M \& Rizvi Q (2003). Effect of different temperatures and host pants on the developmental behaviour of lemon butterfly, Papilio demoleus. Indi $J$ Entomol 65: 496-499.

13. Schiestl FP \& Schluter PM (2009). Floral isolation, specialized pollination, and pollinator behavior in orchids. Апnи Rev Entomol 54: 425-46.
14. Chen XY WEN RZ \& Chen HD (2004). Observation on the bionomics of Papilio demoleus in Guangzhou. Entomol Knowle 41: 169-171.

15. Narayanamma VL Savithri $P$ \& Rao R (2001). Influence of citrus orange host plant. Indian J Plant Prot 29: 140-141.

16. Resham B Fanindra PN \& Butani DK (1988). Insect pests of citrus in Nepal and their control. Pestology 10: 24-27.

17. Rajendra B Kirpal S Bhan R \& Shing, $K$ (1997). Bionomics of lemon butterfly, Papilio demoleus L. on Citrus reticulate. Pest Management and Eco Zoo India 5: 37-41.

18. Fenster CB Armbruster WS Wilson $\mathrm{P}$ Dudash MR \& Thomson JD (2004). Pollination syndromes and floral specialization. Anпи Rev Ecol Syst 35: $375-403$.

19. Singh SP (1993). Species composition and diapauses in citrus butterflies. $J$ Insect Sci 6(1): 48-52.

20. Sharifi S Zarea N (1989). Biology of the citrus Butterfly, P. demoleus (Lepidoptera: Papilionidae). Ann Ento Soci America 63: 1211-1213.

21. Bhan R \& Singh K (1997). Bionomics of lemon butterfly, Papilio demoleus L. on Citrus reticulate Blanco. Pest Manage Econo Zoo 5: 37-41. 